Keywords: Ion Exchange

Cesium Removal

Gamma Monitoring

Retention: Permanent

\title{
Triplicate Sodium Iodide Gamma-Ray Monitors for the Small Column Ion Exchange Program
}

\section{A.H. Couture}

August 2011

Savannah River National Laboratory Savannah River Nuclear Solutions, LLC Aiken, SC 29808

Prepared for the U.S. Department of Energy under contract number DE-AC09-08SR22470.

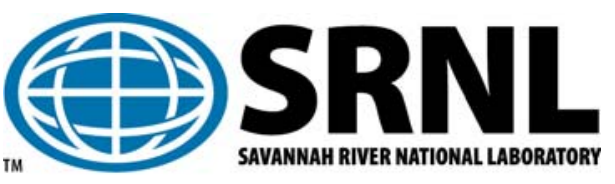


SRNL-STI-2011-00510

Revision 0

\section{DISCLAIMER}

This work was prepared under an agreement with and funded by the U.S. Government. Neither the U.S. Government or its employees, nor any of its contractors, subcontractors or their employees, makes any express or implied:

1. warranty or assumes any legal liability for the accuracy, completeness, or for the use or results of such use of any information, product, or process disclosed; or

2. representation that such use or results of such use would not infringe privately owned rights; or

3. endorsement or recommendation of any specifically identified commercial product, process, or service.

Any views and opinions of authors expressed in this work do not necessarily state or reflect those of the United States Government, or its contractors, or subcontractors.

\section{Printed in the United States of America \\ Prepared for \\ U.S. Department of Energy}




\section{EXECUTIVE SUMMARY}

This technical report contains recommendations from the Analytical Development (AD) organization of the Savannah River National Laboratory (SRNL) for a system of triplicate Sodium Iodide (NaI) detectors to be used to monitor Cesium-137 $\left({ }^{137} \mathrm{Cs}\right)$ content of the Decontaminated Salt Solution (DSS) output of the Small Column Ion Exchange (SCIX) process. These detectors need to be gain stabilized with respect to temperature shifts since they will be installed on top of Tank 41 at the Savannah River Site (SRS). This will be accomplished using NaI crystals doped with the alpha-emitting isotope, Americium-241( $\left.{ }^{241} \mathrm{Am}\right)$. Two energy regions of the detector output will be monitored using single-channel analyzers (SCAs), the ${ }^{137} \mathrm{Cs}$ full-energy $\gamma$-ray peak and the ${ }^{241} \mathrm{Am}$ alpha peak. The count rate in the gamma peak region will be proportional to the ${ }^{137} \mathrm{Cs}$ content in the DSS output. The constant rate of alpha decay in the NaI crystal will be monitored and used as feedback to adjust the high voltage supply to the detector in response to temperature variation. An analysis of theoretical ${ }^{137} \mathrm{Cs}$ breakthrough curves was used to estimate the gamma activity expected in the DSS output during a single iteration of the process. Count rates arising from the DSS and background sources were predicted using Microshield modeling software. The current plan for shielding the detectors within an enclosure with four-inch thick steel walls should allow the detectors to operate with the sensitivity required to perform these measurements. Calibration, testing, and maintenance requirements for the detector system are outlined as well. 
SRNL-STI-2011-00510

Revision 0

\section{REVIEWS AND APPROVALS}

AUTHOR:

A.H. Couture, Materials Characterization \& Nuclear Measurements

Date

TECHNICAL REVIEW:

R.S. Lee, Analytical Development

Date

R.A. Dewberry Jr., Materials Characterization \& Nuclear Measurements

Date

APPROVAL:

R. H. Young, Manager

Date

Materials Characterization \& Nuclear Measurements

M.J. Barnes, Manager

Date

Analytical Development

F.M. Pennebaker, Manager

Date

Environmental \& Chemical Process Technology Research Programs

T.H. Huff, Manager

Date

SRR-SCIX Engineering 


\section{TABLE OF CONTENTS}

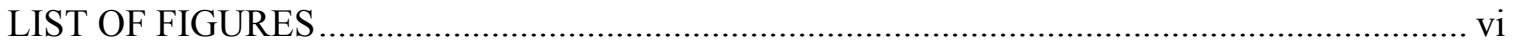

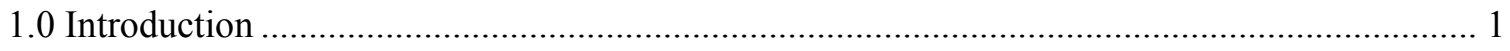

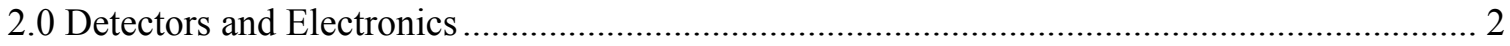

3.0 Incorporation into the Distributed Control System …........................................................... 3

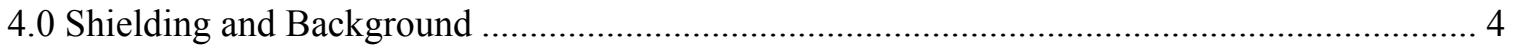

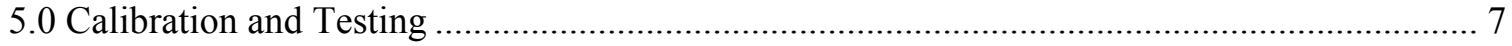

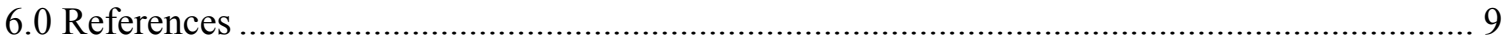




\section{LIST OF FIGURES}

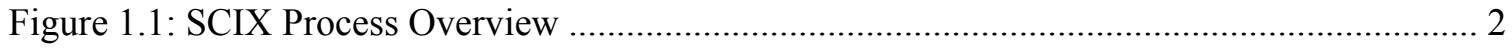

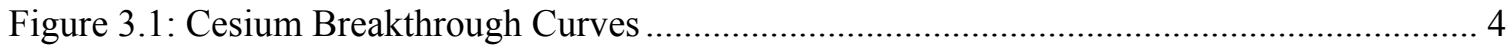

Figure 4.1: Plot of Gamma Flux vs. Pipe Length seen by NaI detector........................................ 5

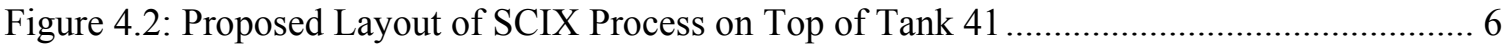

Figure 4.3: Loading of Cesium on Ion Exchange Columns. ........................................................ 7 


\section{LIST OF ABBREVIATIONS}

\begin{tabular}{|c|c|}
\hline $\mathrm{AD}$ & Analytical Development \\
\hline $\mathrm{Am}$ & Americium \\
\hline $\mathrm{Ba}$ & Barium \\
\hline cpm & Counts per Minute \\
\hline Cs & Cesium \\
\hline CSS & Clarified Salt Solution \\
\hline CST & Crystalline Silicotitanate \\
\hline DCS & Distributed Control System \\
\hline DSS & Decontaminated Salt Solution \\
\hline DWPF & Defense Waste Processing Facility \\
\hline $\mathrm{keV}$ & Kiloelectron Volt \\
\hline gpm & Gallon per Minute \\
\hline IXC & Ion Exchange Column \\
\hline $\mathrm{MeV}$ & Megaelectron Volt \\
\hline $\mathrm{MCA}$ & Multi-Channel Analyzer \\
\hline MST & Monosodium Titanate \\
\hline $\mathrm{NaI}$ & Sodium Iodide \\
\hline RMF & Rotary Microfilter \\
\hline SCA & Single-Channel Analyzer \\
\hline SCIX & Small Column Ion Exchange \\
\hline SPF & Saltstone Production Facility \\
\hline $\mathrm{Sr}$ & Strontium \\
\hline SRNL & Savannah River National Laboratory \\
\hline SRD & Spent Resin Disposal \\
\hline
\end{tabular}


SRNL-STI-2011-00510

Revision 0

SRS

UDR

ZAM

Savannah River Site

Universal Digital Ratemeter

Zhang, Anthony, Miller 


\subsection{Introduction}

The Analytical Development (AD) organization of the Savannah River National Laboratory (SRNL) was tasked with providing a recommendation for a system of three redundant Sodium-Iodide ( $\mathrm{NaI})$ detectors to monitor the Cesium-137 $\left({ }^{137} \mathrm{Cs}\right)$ content in the Decontaminated Salt Solution (DSS) effluent being sent to Tank 50 from the Small Column Ion Exchange (SCIX) process at the Savannah River Site (SRS). This will be done by detecting the 662 kiloelectron volt (keV) $\gamma$-ray emitted by the daughter nuclei, Barium-137m $\left({ }^{137 m} \mathrm{Ba}\right)$. Recommendations for the SCIX gamma monitors will address several issues: the required detectors and electronics, incorporation into the SCIX Distributed Control System (DCS), shielding and background rates, initial testing, calibration, and maintenance.

The purpose of SCIX is to remove and concentrate high-level radioisotopes from SRS salt waste resulting in two waste streams. The concentrated high-level waste containing ${ }^{137} \mathrm{Cs}$ will be sent to the Defense Waste Processing Facility (DWPF) for vitrification and the low-level DSS will be sent to the Saltstone Production Facility (SPF) to be incorporated into grout. First, Monosodium Titanate (MST) is mixed with the salt waste in Tank 41 to remove Strontium-90 $\left({ }^{90} \mathrm{Sr}\right)$ and actinides. The insoluble solids such as suspended MST and sludge will then be removed from the salt waste by a series of four Rotary Microfilter (RMF) units producing Clarified Salt Solution (CSS), which will contain up to $2.625 \mathrm{Ci} / \mathrm{gal}^{1}$ of ${ }^{137} \mathrm{Cs}$. The CSS will then be pumped at $\sim 10$ gallons per minute (gpm) through two Ion Exchange Columns (IXCs) containing Crystalline Silicotitanate (CST) sorbent, which will remove ${ }^{137} \mathrm{Cs}$ from the solution, producing $\mathrm{DSS}^{1}$. The region of each IXC containing CST will have an inner diameter of 27.375" and a height of 233.25 " as per preliminary vendor drawings with a volume of 79.4 cubic $\mathrm{ft}$ ( $\sim 600$ gal); however, the IXCs will contain an interior cooling line that will occupy $\sim 5 \%$ of this volume ${ }^{2}$. During production, the columns will each contain 440 gallons of CST resin with a ${ }^{137} \mathrm{Cs}$ loading capacity of up to $2300 \mathrm{Ci} /$ gal, thus a fully loaded IXC can contain a total of $1.0 \times 10^{6} \mathrm{Ci}$ of activity ${ }^{1}$. The DSS effluent from SCIX can have an average ${ }^{137} \mathrm{Cs}$ content of no more than $6 \mathrm{nCi} / \mathrm{g}(0.028 \mathrm{mCi} / \mathrm{gal}){ }^{3}$. The conversion between $\mathrm{nCi} / \mathrm{g}$ and $\mathrm{mCi} / \mathrm{gal}$ is based on a DSS density of $1.25 \mathrm{~g} / \mathrm{mL}$. The DSS effluent will be pumped from SCIX to Tank 50 through a $1 \frac{1}{2}$ " Schedule $40 \mathrm{~S}$ pipe $^{2}$ (stainless steel, 1.90 " outer diameter, 0.145 " wall thickness). This pipe should be configured with a vertical rise after the gamma monitors to ensure the pipe is completely filled with DSS during operation. The two IXCs will be operated in series in a "lead-lag" configuration. Before the DSS stream reaches an average ${ }^{137} \mathrm{Cs}$ concentration of $6 \mathrm{nCi} / \mathrm{g}$, the spent CST will be sluiced out from the lead column to the Spent Resin Disposal (SRD) unit, ground, and sent to Tank 40, the DWPF feed tank. The column will then be refilled with fresh CST and the role of lead and lag column will be switched ${ }^{3}$. A diagram outlining the SCIX process may be found in Figure 1.1. 


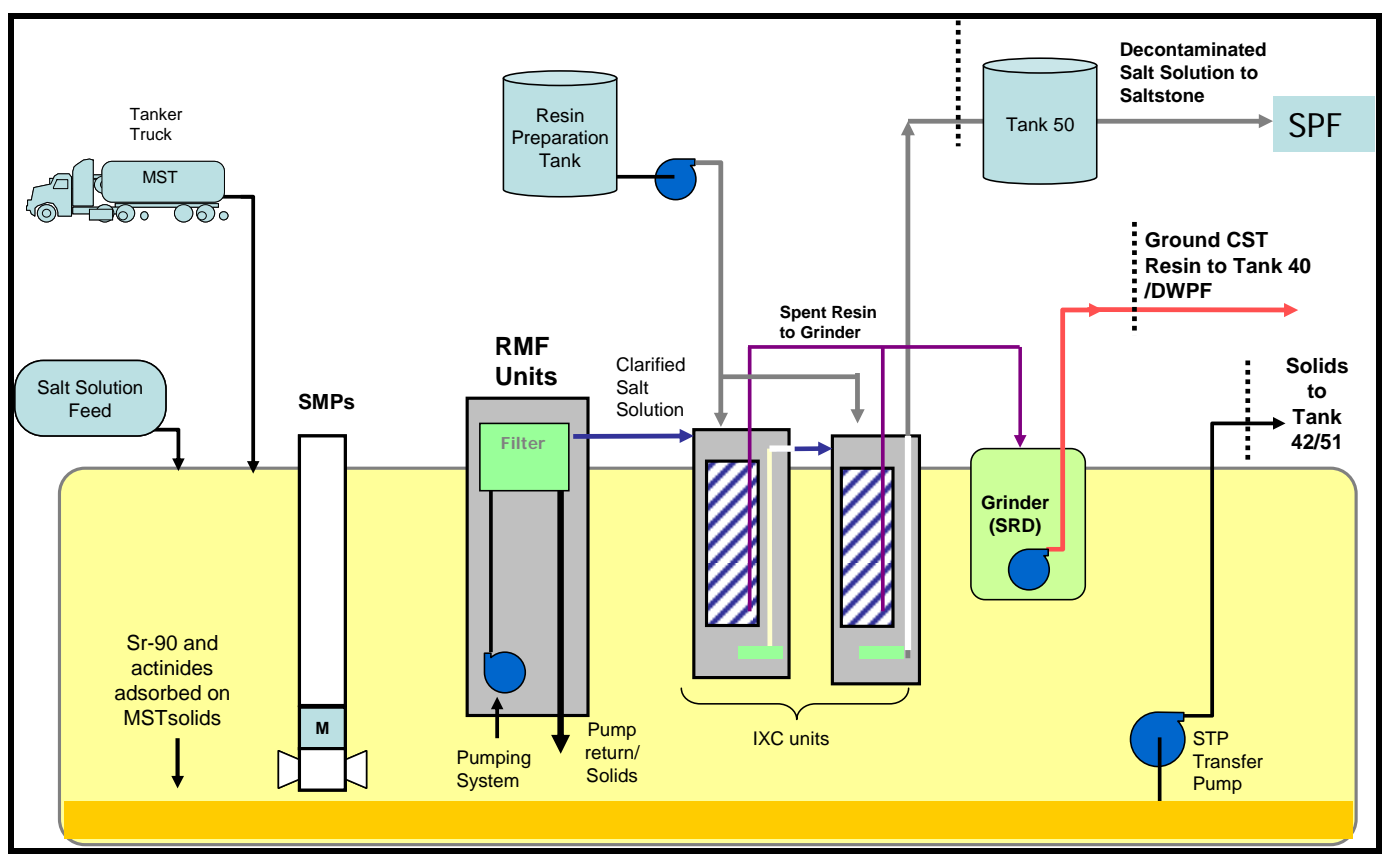

Figure 1.1: SCIX Process Overview

\subsection{Detectors and Electronics}

A major difficulty in operating gamma monitors at the SRS Tank Farm is the temperature fluctuations to which the detectors will be exposed. The ambient temperature at the SRS can vary from 15 to $110^{\circ} \mathrm{F}$. Detector gains are sensitive to changes in temperature, an effect that must be taken into account to provide a reliable system for ${ }^{137} \mathrm{Cs}$ detection. For this reason, the NaI detectors being used to monitor the ${ }^{137} \mathrm{Cs}$ content in the DSS should be doped with an Americium-241 ( $\left.{ }^{241} \mathrm{Am}\right)$ source. The purpose of the ${ }^{241} \mathrm{Am}$ is to act as a pulser, providing a constant source of alpha radiation with a gamma-equivalent energy between 2.85 and 3.15 megaelectron volts $(\mathrm{MeV})$ depending on the construction of the individual detectors ${ }^{4}$. The detector response to these alphas will be well separated in energy from the $662 \mathrm{keV}{ }^{137} \mathrm{Cs} \gamma$-ray line. Two singlechannel analyzers (SCAs) will be required for each detector, one to monitor the alpha radiation and one to monitor the ${ }^{137} \mathrm{Cs}$ gamma radiation. The output of each SCA will be sent to a ratemeter. The output of the ratemeter monitoring the ${ }^{241} \mathrm{Am}$ alphas will be used in a feedback circuit to adjust the high-voltage supply for the detector, stabilizing the gain in response to temperature fluctuations. An output signal will be sent to the SCIX DCS from the ${ }^{137} \mathrm{Cs}$ ratemeter indicating the amount of activity in the DSS stream.

A system is available from Fluke Biomedical that possesses these capabilities. It consists of a 2 " diameter by 2 " thick NaI crystal containing a small capsule of ${ }^{241} \mathrm{Am}$. The crystal is coupled to a photomultiplier tube/preamplifier assembly all encased within a 2.5 " diameter by 10.5 " long stainless steel housing (Model \# 943-237A) ${ }^{5}$. The preamplifier is able to drive the detector anode signal up to $1500 \mathrm{ft}$ through $50 \Omega$ coaxial cable. Also provided by Fluke is the Model 942A-200 series Universal Digital 
Ratemeter $^{6}$ (UDR) that is available with a Model 942-200-90 SCA/Americium Regulator ${ }^{7}$ that plugs into an option board bus on the UDR motherboard. The system can operate between 32 and $122^{\circ} \mathrm{F}$ with a maximum rate of change of $9^{\circ} \mathrm{F} / \mathrm{hr}$. Despite the fact that this detector system incorporates gain stabilization with respect to temperature changes, it would be useful to maintain the temperature of the detector enclosure above the minimum temperature of the DSS $\left(\sim 70^{\circ} \mathrm{F}\right)$ and below $122^{\circ} \mathrm{F}$. The relative humidity may range between 0 and $95 \%$, but must be non-condensing. The enclosure should be designed such that rainwater will not leak into it.

\subsection{Incorporation into the Distributed Control System}

The UDR's have the capability of sending various types of signals to the DCS to indicate the ${ }^{137} \mathrm{Cs}$ content in the effluent DSS. It may send either $4-20 \mathrm{~mA}$ or $0-10 \mathrm{~V}$ signals logarithmically proportional to the count rate within the SCA window of the NaI detector. The upper and lower limits of the signal must be a power of 10 and can be set between $10^{-9}$ and $10^{9}$ counts per minute $(\mathrm{cpm})$ with a minimum range of a decade. It also has the capability of providing several contact relays, which can be programmed to trip at various setpoints ${ }^{6}$.

To determine the average ${ }^{137} \mathrm{Cs}$ content in the DSS being sent to Tank 50 during a run, the following relationship is used:

$$
\left\langle\frac{N_{G S}}{V}\right\rangle=\frac{1}{V} \Sigma_{i}\left\{\left[\frac{N_{G_{R}}}{V}\right]_{i} \cdot\left[\frac{d V}{d t}\right]_{l}, \Delta t\right\}
$$

where,

$$
\begin{aligned}
{\left[\frac{v G s}{V}\right]_{t} } & =\text { instantaneous }{ }^{137} \mathrm{Cs} \text { content } \\
{\left[\frac{d V}{d t}\right]_{t} } & =\text { DSS flow rate } \\
\Delta t & =\text { sampling interval } \\
V & =\text { total volume processed }
\end{aligned}
$$

To obtain the instantaneous ${ }^{137} \mathrm{Cs}$ content from the count rate measured by the detector system, conversion factors must be supplied to the DCS. These conversion factors will depend upon the geometry of the detector and DSS effluent pipe, the efficiency of the $\mathrm{NaI}$ detector, and the background within the SCA window. The detector efficiency may be temperature dependent and the background could vary over the lifetime of the system if ${ }^{137} \mathrm{Cs}$ is deposited on the walls of the transfer lines. These factors will have to be determined during the initial testing and periodic evaluations of the detector system.

The relationship between the instantaneous and average ${ }^{137}$ Cs content in the DSS should depend on a number of factors: the ${ }^{137} \mathrm{Cs}$ content, density, temperature, and flow rate of CSS entering the IXC, as well as the quantity and distribution of ${ }^{137} \mathrm{Cs}$ loaded on the CST at the beginning of a batch. Figure 3.1 shows ${ }^{137} \mathrm{Cs}$ breakthrough curves 
modeled using the Zhang, Anthony, Miller (ZAM) code based on fresh CST and CSS containing $2.36 \mathrm{Ci} / \mathrm{gal}$ of ${ }^{137} \mathrm{Cs}$ with a density, temperature, and flow rate of $1.25 \mathrm{~g} / \mathrm{mL}$, $25^{\circ} \mathrm{C}$, and $10 \mathrm{gpm}$, respectively ${ }^{3}$. These parameters correspond to SCIX Batch $2 \mathrm{x}$ from Reference 3, which was chosen because it was predicted to have the highest ${ }^{137} \mathrm{Cs}$ loading on the IXCs of all the SCIX batches modeled. This model predicts that 520,000 gallons of CSS can be processed before the $6 \mathrm{nCi} / \mathrm{g}$ average limit is reached. This corresponds to an instantaneous ${ }^{137} \mathrm{Cs}$ content of $0.69 \mathrm{mCi} / \mathrm{gal}$ or $143 \mathrm{nCi} / \mathrm{g}$. Rather than integrating the ${ }^{137} \mathrm{Cs}$ content of the DSS, an upper limit to the instantaneous ${ }^{137} \mathrm{Cs}$ content may be imposed. This will have to be chosen carefully so as not to exceed the $6 \mathrm{nCi} / \mathrm{g}$ average limit, but not limit the efficiency of the SCIX process. If the upper limit is taken to be 6 $\mathrm{nCi} / \mathrm{g}$, the modeled batch will need to be stopped at 454,000; a $12.7 \%$ decrease in process volume. Since this model was based upon a run with fresh CST, the actual decrease in overall process volume per batch during normal operations would be greater because each batch $\mathrm{I}$

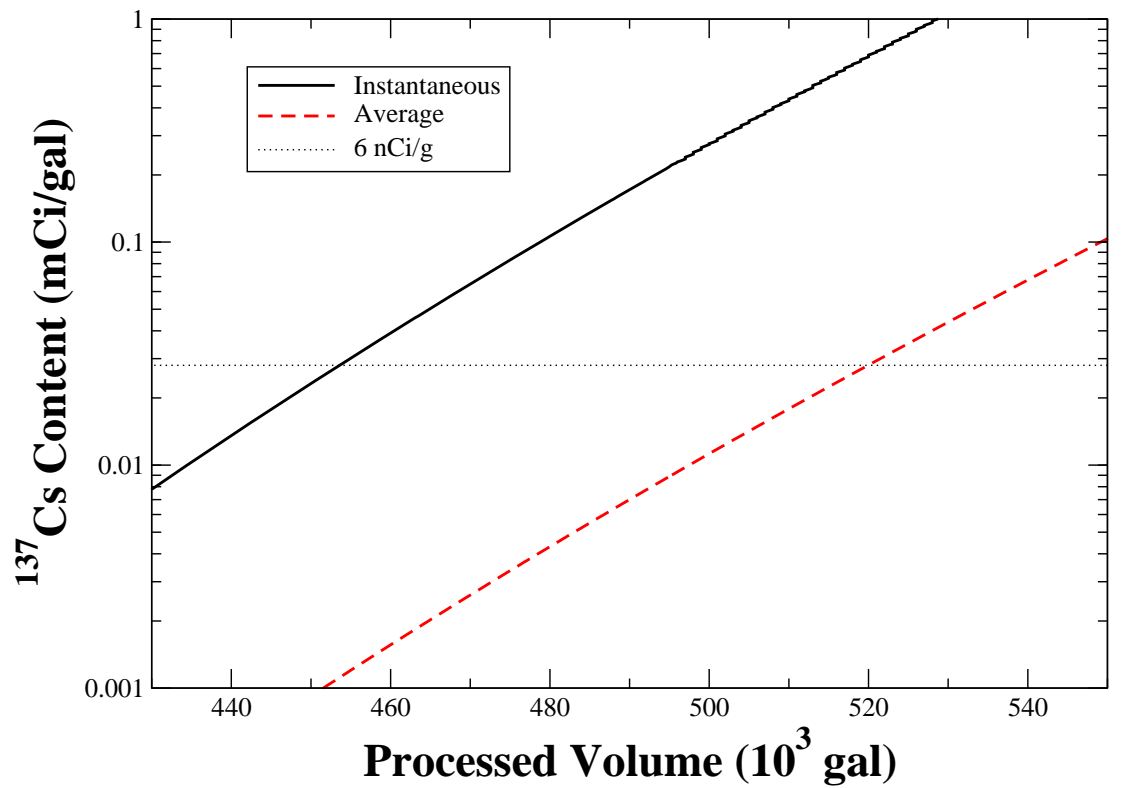

Figure 3.1: Comparison of Instantaneous and Average ${ }^{137}$ Cs Breakthrough Curves ${ }^{3}$.

\subsection{Shielding and Background}

The gamma flux incident on the NaI detectors was calculated using Microshield from Grove Software, Inc. These calculations were performed for $1 \frac{1 / 2}{2}$ Schedule 40S pipes of different lengths filled with DSS containing varied quantities of ${ }^{137} \mathrm{Cs}$. The DSS was modeled as water with a density of $1.25 \mathrm{~g} / \mathrm{cm}^{3}$ and the pipe as $7.8 \mathrm{~g} / \mathrm{cm}^{3}$ iron. Three different levels of ${ }^{137} \mathrm{Cs}$ activity in the DSS were modeled: $0.001 \mathrm{mCi} / \mathrm{gal}$, as a conservative lower limit to the required sensitivity, $0.028 \mathrm{mCi} / \mathrm{gal}$, the average activity allowed during a batch, and $0.69 \mathrm{mCi} / \mathrm{gal}$, the instantaneous activity predicted when the average activity reaches its maximum allowed value. The dose point was placed 2 " from 
the center and 3" from one end of the pipe. The length of pipe was varied from 6 to 18 ". At pipe lengths greater than 12", the gamma flux was essentially constant. Thus, detectors spaced more than a foot apart without any intermediate shielding will be essentially independent. Figure 4.1 shows a plot of this effect for DSS containing 0.001 $\mathrm{mCi} / \mathrm{gal}{ }^{137} \mathrm{Cs}$, though the same trend appeared in all three concentrations studied. An inch of steel between the three detectors would further ensure independence. The unscattered photon flux from a 6" length of pipe at the dose point is predicted to be 2.1, 61, and 1510 photons $/ \mathrm{cm}^{2} \cdot \mathrm{s}$, respectively for the three ${ }^{137} \mathrm{Cs}$ concentrations given above. Roughly $75 \%$ of $662 \mathrm{keV} \gamma$-rays incident upon a 2 " diameter by 2" thick NaI crystal will deposit energy in the crystal. This will occur through one of two processes; the photoelectric effect or Compton scattering. Gamma-rays that interact through the photoelectric effect deposit all of their energy in the detector producing a narrow photopeak in the measured spectrum. The SCA window will be set around this photopeak. Compton-scattered $\gamma$-rays only deposit a portion of their energy in the detector producing low-energy counts in the spectrum. The SCA window should remove most of these events from the analysis. The ratio of counts in the $662 \mathrm{keV}$ photopeak to total counts should be $50-60 \%{ }^{8}$. Thus the $662 \mathrm{keV}$ photopeak detection efficiency should be approximately $35-45 \%$, producing count rates between $10^{3}$ and $10^{6} \mathrm{cpm}$. If buildup is included in tl window shor

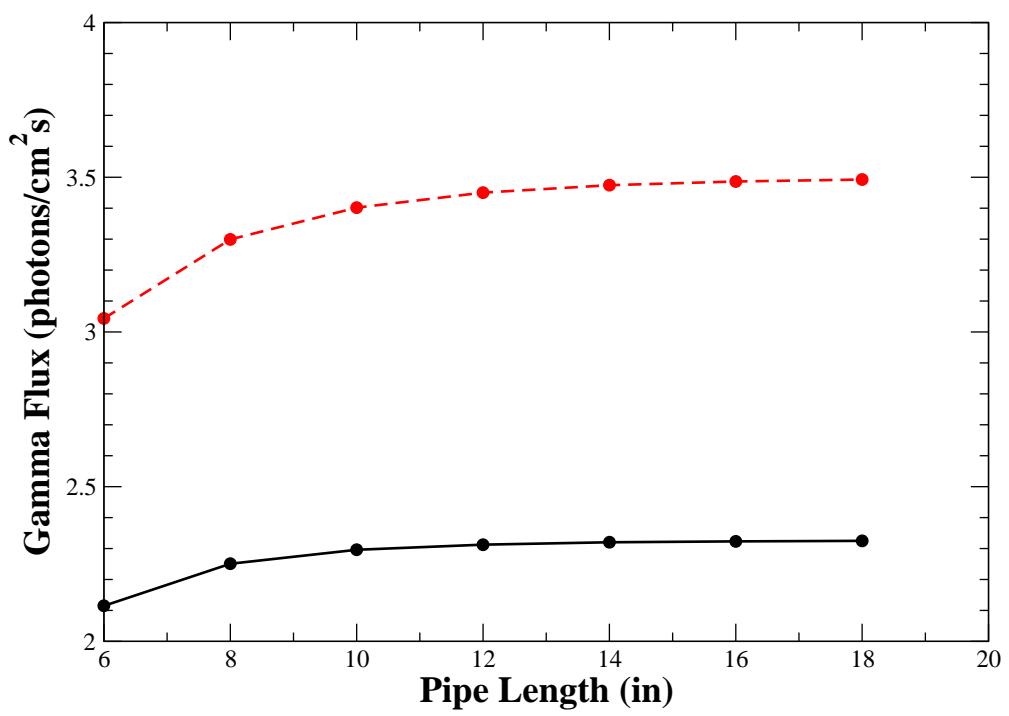
Figure 4.1: Gamma flux vs. Pipe Length DSS containing $0.001 \mathrm{mCi} / \mathrm{gal}{ }^{137} \mathrm{Cs}$. The black line
gives the unscattered flux and the red dashed line includes buildup.

Another concern is the background rate from the SCIX columns, which may hold up to $1.0 \times 10^{6} \mathrm{Ci}$ of ${ }^{137} \mathrm{Cs}$. Figure 4.2 shows the planned layout of the SCIX equipment. The closest IXC is approximately $13^{1 / 2}$ ' horizontally from the gamma monitors. The gamma monitors will be enclosed within a steel box with 4" walls. This box will be approximately 3' above a 5' layer of concrete and the top of the IXC resin bed will lie slightly more than $10^{1 / 2}$ ' below the top of the concrete. Microshield predicts that the background in the gamma peak from a full ICX will be at least 6 orders of magnitude 
below the expected signal from the DSS. The buildup flux will also be insignificant. Incorporating 4" of steel shielding around the gamma monitors into the calculation lowers the background by an additional 3 orders of magnitude. Shielding calculations performed using ISOTOPIC software from Ametek agree with these results.

The SRD unit will be even closer to the gamma monitors than the IXCs. However, it should contain only residual ${ }^{137} \mathrm{Cs}$ when the gamma monitors are online since the SRD unit will only be used to dispose of spent CST after the completion of a SCIX batch. Microshield calculations indicate that, even if the SRD unit was completely full of CST containing $2300 \mathrm{Ci} /$ gal of ${ }^{137} \mathrm{Cs}$, the 5 ' of cement and 4" of steel should eliminate any significant background in the gamma monitors. This calculation is based upon an SRD unit with a resin volume defined by a 15 ' height and 35 " diameter" These shielding calculations assume the geometry described above; modifications to this geometry will require additional calculations to ensure detector sensitivity.

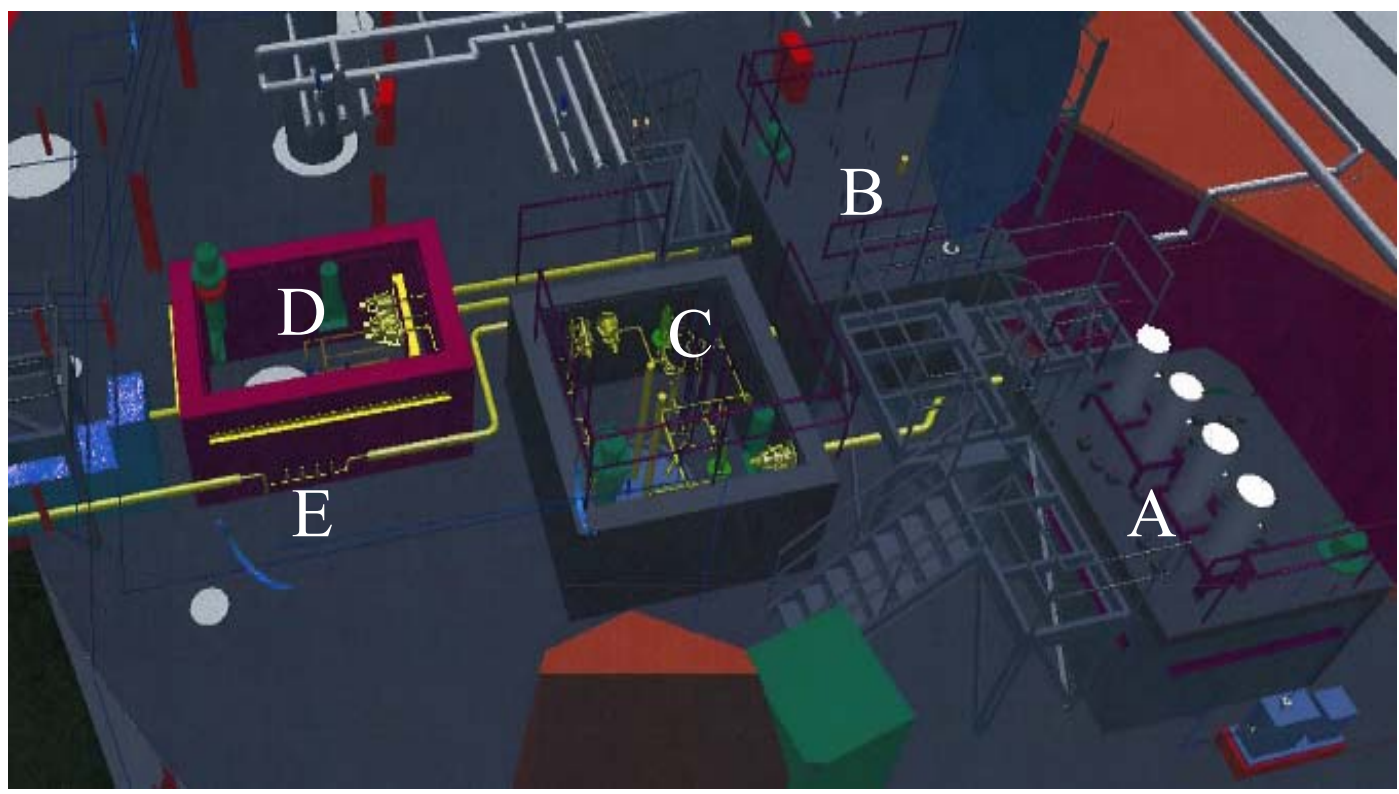

Figure 4.2: Proposed Layout of SCIX Process on Top of Tank 41. This rendering includes (A) the Rotary Microfilters, (B and C) the two Ion Exchange Columns, (D) the grinder, and (E) the gamma monitors. The huts around (C) and (D) will have roofs. The gamma monitors will sit inside an enclosure with 4" steel walls (not shown).

The gamma monitors will detect the activity of ${ }^{137 m} \mathrm{Ba}$, the daughter of ${ }^{137} \mathrm{Cs}$. All gamma flux calculations produced in this report are based on the assumption that the two radionuclides will be in secular equilibrium; meaning for every Curie of ${ }^{137} \mathrm{Cs}$ there should be $0.947 \mathrm{Ci}$ of ${ }^{137 \mathrm{~m}} \mathrm{Ba}$ present. However, increased ${ }^{137 \mathrm{~m}} \mathrm{Ba}$ concentrations in the DSS relative to ${ }^{137} \mathrm{Cs}$ could arise from two sources. As ${ }^{137} \mathrm{Cs}$ that has loaded onto column decays, there is the potential that ${ }^{137 \mathrm{~m}} \mathrm{Ba}$ could break loose from the CST and escape in the DSS. This scenario is unlikely. CST captures ${ }^{137} \mathrm{Cs}$ based upon ionic attraction and size. After beta-decay, the charge state of the ion changes from +1 to +2 and the ionic 
radius decreases by $\sim 20 \%{ }^{10}$. The increased ionic attraction to the negative loading sites on the CST and similar size should keep the barium loaded. There will also be ${ }^{137 m} \mathrm{Ba}$ flowing into the IXC and produced from "free-floating" ${ }^{137} \mathrm{Cs}$ within the IXCs. This ${ }^{137 \mathrm{~m}} \mathrm{Ba}$ might not load onto the CST, though experiments conducted at Oak Ridge National Laboratory ${ }^{11}$ and SRNL ${ }^{12}$ indicate that this is not the case. The two resin beds in the IXCs have bed and particle void fractions of 0.5 and 0.24 , respectively ${ }^{3}$. Thus $62 \%$ of the bed volume ( $\sim 550 \mathrm{gal})$ along with the head space ( $\sim 260 \mathrm{gal})$ can be filled with salt solution. At a flow rate of $10 \mathrm{gpm}$, it will take about 80 minutes or 31 half-lives of ${ }^{137 \mathrm{~m}} \mathrm{Ba}$ for the salt solution to traverse the IXCs. Even if the ${ }^{137 \mathrm{~m}} \mathrm{Ba}$ does not load on the CST, at the beginning of a SCIX batch there will be ample time for the ${ }^{137 \mathrm{~m}} \mathrm{Ba}$ to decay before reaching the gamma monitors. However, ${ }^{137} \mathrm{Cs}$ will not be removed from the salt solution until it reaches fresh CST and as the batch progresses this will occur further into the IXCs. Equilibrium will be maintained between the two radionuclides until this point, giving the excess ${ }^{137 \mathrm{~m}} \mathrm{Ba}$ less time to decay before arriving at the gamma monitors. Figure 4.3 shows the cesium column loading profile as predicted by ZAM modeling at the end of a typical SCIX batch ${ }^{3}$. In this scenario, the lead column is completely loaded with ${ }^{137} \mathrm{Cs}$ and the lag column is $30 \%$ loaded. If ${ }^{137 \mathrm{~m}} \mathrm{Ba}$ does not load along with ${ }^{137} \mathrm{Cs}$, the gamma monitors will detect rates 20 times higher than expected for the actual ${ }^{137} \mathrm{Cs}$ cr

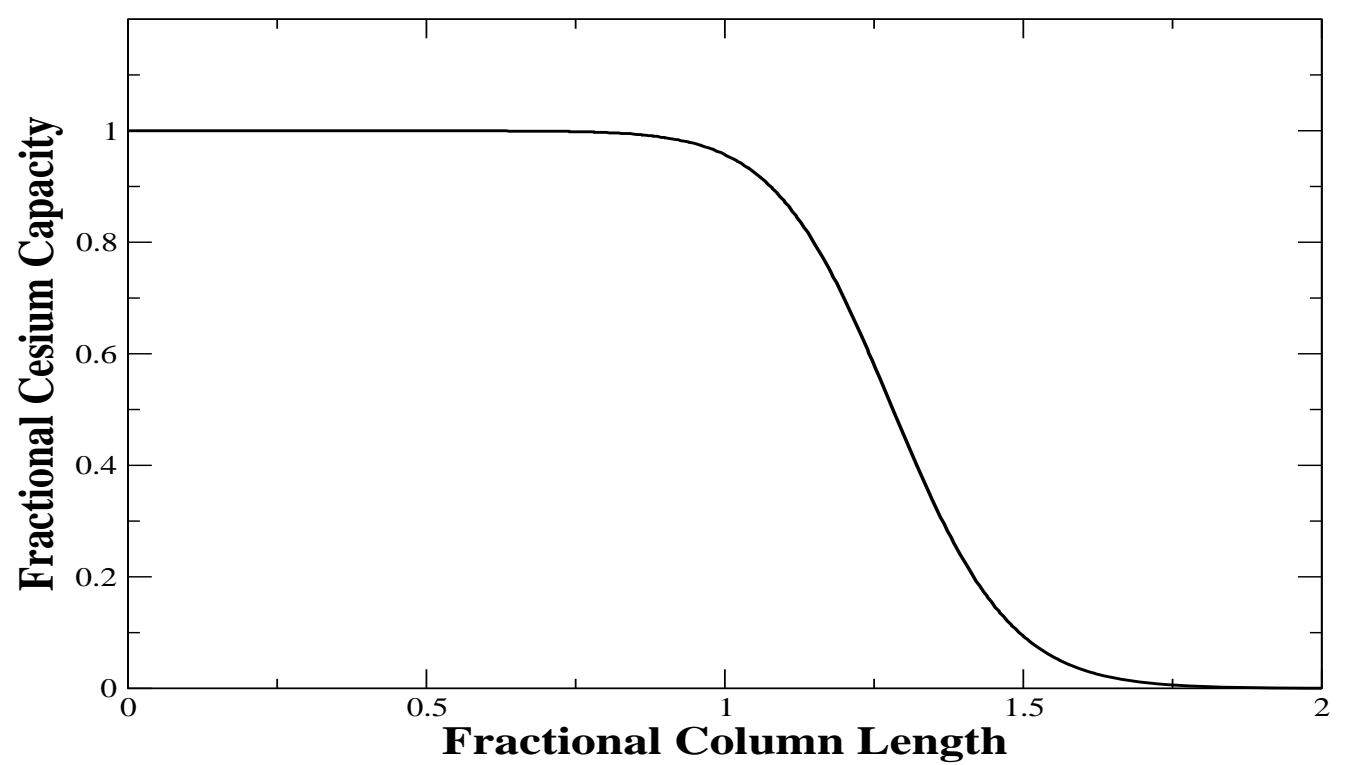

Figure 4.3: Cesium Loading Profile on the Two IXC at the End of a Typical SCIX Batch Based on ZAM Modeling3.

\subsection{Calibration and Testing}

Initial testing and calibration of the detectors will take place at SRNL. Calibration sources containing ${ }^{137} \mathrm{Cs}$ suspended in a $1.15 \mathrm{~g} / \mathrm{mL}$ epoxy matrix enclosed within 6" long 11/2" Schedule 40 S pipes can be purchased from Eckert \& Zeigler 
Analytics Inc. Several sources should be procured spanning the range of activity expected in the DSS. A small chamber will be constructed based on the actual geometry of the gamma monitor enclosure to be installed on the tank top. This chamber will be temperature controlled allowing for variation of the temperature over the range expected when the monitors are in service. A detector and calibration source will be placed within the chamber and measurements will be taken at several temperatures with each of the sources. This calibration will provide the conversion factors between count rate and source activity to be used by the DCS. An error analysis of these conversion factors will be performed by incorporating uncertainties in source activity, counting time, geometry, background, and temperature. During this calibration, the anode signal from the detector will be split using a linear fan-out. One signal from the linear fan-out will be sent to the UDR with SCA/Americium Regulator and the other to a multi-channel analyzer (MCA). The MCA will acquire spectra over the entire energy range of the detector and will allow accurate adjustment of the SCA window for the UDR.

During the first hot runs of the SCIX process, the same MCA setup described above should be used to monitor the DSS. This will enable characterization of background rates and gain stability. Over the course of the first run, tests should be performed to ensure that the detectors are adequately shielded and ${ }^{137 \mathrm{~m}} \mathrm{Ba}$ is in secular equilibrium with the ${ }^{137} \mathrm{Cs}$ in the DSS. To demonstrate this, a simple test can be performed. First two valves, one upstream from the gamma monitors and one downstream, should be closed. Care should be taken to keep the effluent pipe completely full of DSS. If ${ }^{137 \mathrm{~m}} \mathrm{Ba}$ levels are elevated, they should diminish to the level of ${ }^{137} \mathrm{Cs}$ concentration within several minutes because of the disparity between the decay rates of the two radionuclides. Monitoring the count rate for 5-10 minutes should be sufficient to determine if elevated ${ }^{137 \mathrm{~m}} \mathrm{Ba}$ levels are an issue for the SCIX process. After this, the effluent pipe should be flushed with inhibited water and a short background measurement should be made. After the first SCIX run, an independent analysis of the ${ }^{137} \mathrm{Cs}$ levels in the DSS should be performed and compared to those determined by the gamma monitors to ensure monitor accuracy.

Periodic testing and maintenance of the gamma monitors will be required. Biannual gamma source calibrations should be performed and background measurements be taken to ensure ${ }^{137} \mathrm{Cs}$ is not being deposited as scale build-up on the interior of the effluent pipe. Monitoring of an entire SCIX batch using the MCA setup annually is advisable. Testing of the detector gain stabilization system by varying the temperature within the gamma monitor enclosure should be performed periodically as well. 


\subsection{References}

1. K.D. Marinelli, “Task Requirements and Criteria: Small Column Ion Exchange Program", Savannah River Remediation, U-TC-H-00012, 2011.

2. B.C. Lee, SCIX Ion Exchange Column General Arrangement, CEES-11-284M-0003, Columbia Energy and Environmental Services.

3. F.G. Smith, III, "Modeling CST Ion-Exchange for Cesium Removal from SCIX Batches 1-4.” Savannah River National Laboratory, SRNL-STI-201100181 Rev. 0, 2011.

4. J. Hale, Private Communication. Fluke Biomedical, 2011.

5. 943 Series (Gamma) Technical Datasheet, Fluke Biomedical, 2006.

6. 942A-200 Universal Digital Ratemeter Operator Manual, Fluke Biomedical, 2011.

7. Victoreen 942-100-90 and 942-200-90 Single Channel Analyzer/Americium Regulator Operator Manual, Fluke Biomedical, 2005.

8. Efficiency Calculations for Selected Scintillators. St. Gobain Ceramics \& Plastics, Inc., 2008.

9. T.E. Brooks, II. Private Communication. Savannah River Remediation, 2011.

10. R.D. Shannon, "Revised Effective Ionic Radii and Systematic Studies of Interatomic Distances in Halides and Chalcogenides." Acta Cryst A32: 751$767,1979$.

11. J. F. Walker, et. al., "Cesium Removal Demonstration Utilizing Crystalline Silicotitanate Sorbent for Processing Melton Valley Storage Tank Supernate: Final Report”, ORNL/TM-13503, April 1998.

12. W.R. Wilmarth, et al., "Reactivity of Crystalline Silicotitanate (CST) and Hazardous Metal/Actinide Loading during Low Curie Salt Use.” Savannah River National Laboratory, WSRC-TR-2004-00588, 2004. 


\section{Distribution:}
A. B. Barnes, 999-W
D. A. Crowley, 773-43A
S. D. Fink, 773-A
B. J. Giddings, 786-5A
C. C. Herman, 999-W
S. L. Marra, 773-A
A. M. Murray, 773-A
F. M. Pennebaker, 773-42A
J. H. Scogin, 773-A
W. R. Wilmarth, 773-A
D. T. Herman, 735-11A
A. M. Behrouzi, 773-66A
C. I. Aponte, $740-5 \mathrm{~A}$
W. J. Vetsch, 773-66A
T. H. Huff, 773-66A
R. E. Edwards Jr., 773-67A
K. K. Roberson, 707-H
D. A. Shedd, 707-H
S. K. Gupta, 773-63A
M. W. Campbell, 773-64A
M. A. Rios-Armstrong, 773-66A
R. H. Young, 773-A
M. J. Barnes, 773-A
S. R. Lee, 773-41A
R. A. Dewberry Jr., 773-41A
A. H. Couture, 703-41A
F. G. Smith III, 703-41A 